\title{
Sexual Steroids and their Receptors Affect Microglia-Mediated Neuroinflammation in Neurodegenerative Diseases
}

\author{
Jiao Jiao Liu, Xi He, Jie Liu and Jing Shan Shi* \\ Key Laboratory of Basic Pharmacology of Ministry of Education and Joint International Research Laboratory of Ethnomedicine of \\ Ministry of Education, China \\ *Corresponding author: Jing Shan Shi, Key Laboratory of Basic Pharmacology of Ministry of Education and Joint International \\ Research Laboratory of Ethnomedicine of Ministry of Education, China
}

\section{ARTICLE INFO}

Received: 画 January 21, 2020

Published: 蔧 January 30, 2020

Citation: Jiao Jiao Liu, Xi He, Jie Liu, Jing Shan Shi. Sexual Steroids and their Receptors Affect Microglia-Mediated Neuroinflammation in Neurodegenerative Diseases. Biomed J Sci \& Tech Res 25(2)2020. BJSTR. MS.ID.004160.

Keywords: Sexual Hormone; Gender Differences; Microglia; Neuroinflammation; Neurodegenerative Diseases

\begin{abstract}
Neurodegenerative diseases have been marked by neuroinflammation and remarkable sexual differences in prevalence and pathology preclinically and clinically. Microglia, the resident innate immune cells in the brain, present sexual dimorphism in terms of number, morphology, and distribution in neurodegenerative diseases, especially in Alzheimer's disease and Parkinson's disease. This sexual dimorphism of microglia play as a big fish in healthy and disorder brain. But the mechanisms for the divergence are not well known. Microglia plays an active role in early healthy male and female brain development, including sexual differentiation and development of neurodegenerative diseases. It has been found that microglia are a key fastener involved in neurodegenerative diseases and sexual steroids, such as estrogen, testosterone, and progesterone, have anti-inflammatory effects on microglia-mediated neuroinflammation. The interaction between sexual hormone and neuroinflammation in male and female's neuroimmune signal catches researchers' eyes at a high rate of speed. Here we focus on recent advances in microglia-mediated neuroinflammation relative with gender differences in neurodegenerative diseases.Keywords: IgA vasculitis; Henoch-Schönlein Purpura; Abdominal Phenotype; Gastrointestinal Endoscopy
\end{abstract}

\begin{abstract}
Abbreviations: AD: Alzheimer's Disease; PD: Parkinson's Disease; POA: Preoptic Area; LPS: Lipopolysaccharide; MCI: Mild Cognitive in Impairment; FTD: Frontotemporal Dementia; PGE2: Prostaglandin E2; ERs: Estrogen Receptors; MS: Multiple Sclerosis; ERE: Estrogen Response Element; P3: Postnatal Day 3; EAE: Experimental Autoimmune Encephalomyelitis; TLR4: Toll-Like Receptor 4; RAS: Renin Angiotensin System; TREM2: Triggering Receptor Expressed on Myeloid Cells; PYD: Pyrin Domain; AIM2: Absent in Melanoma2; ROS: Reactive Oxygen Species; iNOS: inducible Nitricoxide Synthase; Nrf: Nuclear Factor; PPAR- $\gamma$ : Peroxisome Proliferator-Activated Receptor- $\gamma$; PR: Progesterone Receptor; AR: Androgen Receptor
\end{abstract}

\section{Introduction}

Neurodegenerative diseases, including Alzheimer's disease (AD) and Parkinson's disease (PD), are generally featured by neuroinflammation and procedural loss of selectively vulnerable populations of neurons, which lead to cognitive impairment, dementia and decline in motor functions $[1,2]$. The most common pathologies of neurodegenerative diseases are amyloidosis, tauopathies, $\alpha$-synucleinopathies, and transactivation response DNA binding protein 43 (TPD-43) [1]. Moreover, amyloidosis, tauopathies, and $\alpha$-synucleinopathies are all associated with neuroinflammation and microglial activation [3-5]. Through phagocytosing abnormal synaptic constituents of neurons, microglia play active roles in synaptic disorders. Moreover, microglia are also associated with synaptic spreading of tau, which is related to the activation of NLRP3 inflammasome [6]. Early microglia responses predicted an improved cognition in PS2APP amyloid mouse model, which suggested the innate immune system could constitute a more relevant therapeutic target [7]. The prevalent of 
neurodegenerative diseases is increasing, and abundant preclinical and clinical data demonstrate that neurodegenerative diseases disproportionately affect male and female in both prevalence and symptom progression $[8,9]$.

Surprisingly, sexual difference existed in microglia isolated from animals. Moreover, microglia in mice emerged sex divergences in different age, especially in older mice. These studies suggested that microglial gender differences could tend to emerge more eminently in aging and age-related disorders, such as neurodegenerative diseases [10]. Sex differences in neurodegenerative diseases are finally attributed to sexual chromosome and sexual hormone. Such as SRY, a Y-chromosome gene, directly contributes to the gender differences in the 6-OHDA-induced rat model of PD [11]. Furthermore, estrogen act on microglia by attenuating the response to inflammatory stimulation and regulating microglial proliferation [12]. Women are more twice than men to suffer from AD over 65 years old and cognitive decline is more severe in women. On the contrary, PD is more common in men (1:3.5) [13]. In an animal experiment, females have more microglia in several specific brain regions than males in healthy adult rats [14], which may account for gender differences in susceptibility to CNS diseases. Microglia, the resident innate immune cells in the brain, has been long well-documented to be decisive for maintaining the homeostasis of the CNS.

It was reported that the sexual differences of susceptibility to neurodegenerative disorders maybe start with genes [8]. In recent years, sex specificity of microglia has become a hot topic in studies because its immune functions are associated with sexual differentiation in neurodegenerative diseases. Gonadal hormones are paramount importance for microglial sex differences. Modulated by sex hormones, the roles and mechanisms of microglia are different in the process of associated neuroinflammation. Both estrogens and androgens play significantly neuroprotective roles in the adult brain and attenuate multiple aspects of AD- and PD-associated neuropathology $[9,15]$. In addition, the $\mathrm{X}$ chromosome, containing a mass of immune-associated genes, is another connection between immunity and gender. In the developing of female preoptic area (POA), immune-related genes are enriched significantly after the suppression of DNA methyltransferase activity [16]. Therefore, the $\mathrm{X}$ chromosome may influence the immune response in a number of ways, leading to sexual differentiation.

\section{Sexual Dimorphism of Microglia in Healthy and Disorder Brain}

Microglia account for 5 to $15 \%$ of adult no-neuronal cells that varies in distinct brain regions and make up a large number of immune cells of brain. Under physiological conditions, microglia hold uniqueness in location within the brain parenchyma, and they can directly contact with neuron, neural progenitors and other cells in these parenchymas [17]. Microglia act as the central junction between inflammation and neurodegenerative disease [13]. The cell has two major functions: watching over the overall health of neurons and synapses and examining the brain for potential threats and problems. When microglia detect abnormal substances, such as amyloid or damaged cell debris, they become activated and signal to other microglia to execute clean-up tasks orderly $[17,18]$. There are sexual dimorphism of brain regions, including POA of hypothalamus, spinal nucleus of the bulbocavernosus, and developing hippocampus, amygdala, and cortex [19]. Meanwhile, neurons, astrocytes and microglia exhibit gender specificity in cell number, distribution and function [20]. Especially astrocytes, another important immune cells in the brain. However, in the last 10 years, microglia have received more attention about gender than astrocytes (Figure 1).

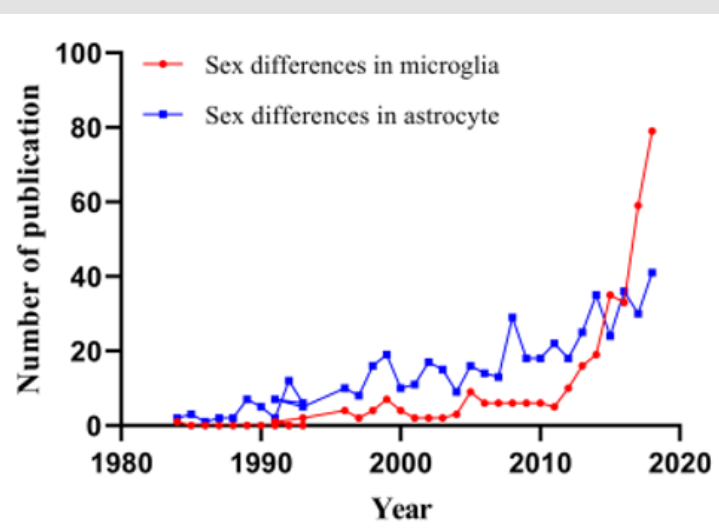

Figure 1: Comparison of publications on microglia and astrocytes in relation to sex in the title or in the abstract.

Human transcriptomes of the brain at different age and the brain span dataset illustrated that gene associated with microglia phagocytic and immune function are highly expressed [21]. The sex-dependent pro-inflammatory profile could be a microglia-specific feature, which is lacking in function-similar macrophages [22]. All of these increasingly affirm these indispensable roles of microglia in sexual dimorphism of the brain (Figure 1). During the process of microglia maturation, sexual dimorphism of microglia has an earlier impact on male than female. Moreover, there is an obvious acceleration in male microglial development after treated with lipopolysaccharide (LPS), while female microglia have no changes during their maturation stages. These documents suggested that male microglia would be more susceptive to neuroinflammative agents, which could answer for rapid aging of microglia and brain dysfunction [23]. Namely, although differences are limited in their colonization patterns, male and female primary microglia have shown several gender-specific divergences in their transcriptomic signatures. Female primary microglia presented higher expression levels of genes related to inflammation, apoptosis, and LPS response [24].

Moreover, through abundant detections of major histocompatibility complex molecules (MHC) from microglia isolated from cortex and hippocampus, higher antigen-presenting capacity of microglia was discovered in naive males [25]. There are more than 500 divergently expressed genes between males and females [22]. A report about molecular signature analysis 
of transcription factors suggested NF- $\mathrm{B}$, a transcription factor associated with the regulation of genes, more expressed in males than females. Microglia isolated from female mice showed a neuroprotective phenotype independent of hormonal cues, which was retained when these neuroprotective microglia were transferred into brains of male mice [22]. Analogously, subsequent studies revealed transcriptomic features of male microglia towards pro-inflammatory functions and luciferase activities were 2.4time higher than female microglia [25]. There are numeral and morphological variances in different brain regions of female and male rodents [26]. Amygdala, POA, hippocampus and cortex are the main brain regions in which microglial sex differences [27-30]. In the developing POA, there are more ameboid-shaped microglia in male brains, while female brains possess more surveying microglia, which suggests that the interaction between microglia and gonadal hormones play a crucial role in the development of the POA $[28,31]$.

\section{Sex Dimorphism in Prevalence and Development of Dementia}

$\mathrm{AD}$ is the most common one of neurodegenerative diseases, with more than 35.6 million persons worldwide estimated to be affected. The number of Alzheimer's patients is expected to almost double every 20 years and will add to 65.7 million in 2030 and to 115.4 million in 2050 [32]. A recent estimate suggested that the global costs for dementia will be 9.12 trillion in 2050, which is more 4.8 folds than the prediction made by the world Alzheimer Report 2015 [33]. One clinical-pathologic study reported that the incidence of $\mathrm{AD}$ is higher in women, exactly 1.33 times than in men aged over 70 years old. This higher incidence in women was observed more previously from 60-64 years old to 95 years old [34,35]. A review discussed key differences between male and female patients with $\mathrm{AD}$ as follows: firstly, men and women undergoing $\mathrm{AD}$ present diverse cognitive and psychiatric symptoms, and females present rapider cognitive decline after diagnosed with mild cognitive in impairment (MCI) or dementia.

Secondly, women have more neuronal tangles in both mesial temporal and neocortical areas. Thirdly, the rate and pattern of brain atrophy vary among AD patients of different genders, women had more AD pathologic diagnosis, especially had more tau tangles density. MCI found that atrophy of brain is rapider in females than in males [36]. The gender difference in AD incidence may be related to age [37]. However, no interaction was found between gender and age, and no linear association between age and AD pathologies, which similarly attested that women have a higher incidence of $\mathrm{AD}$ than men, regardless of age [38]. Frontotemporal dementia (FTD) is one of the major progressive neurodegenerative diseases. Similar to other types of dementia, much evidence suggests that neuroinflammation is a major factor of the pathogenic process, involving excessive microglial activation, astrocytosis, cortical inflammation, and divergent expression of inflammatory cytokines in the periphery [39]. A meta-analysis referring to sex differences in FTD revealed the same outcome as other dementias-a higher prevalence of female patients with GRN-relative FTD than male patients [40].

Under basal conditions and in the presence of proinflammatory stimuli, male microglia showed a markedly increased migratory capacity compared with female microglia in vitro. Oppositely, female microglia exhibited significant enhanced basal and stimulated phagocytic activity [41]. Anti-aging drugs, such as acarbose, 17-a-estradiol and nordihydroguaiaretic acid, reduced the number of microglia, as well as age-associated overproduction of TNF-a in the hypothalamus of male UM-HET3 mice, but these effects are not founded in female mice, which suggests that microglial activation in the hypothalamiccould is effected by drug-induced changes in a gender-specific manner [42]. That sex-dimorphism preference in neurodegeneration might be meditated by estrogen-induced kallikrein-8 (KLK8) overproduction which emerged in neuronal and microglial cells long before AD pathology [43].

\section{Mechanisms: The Role of Estrogen and Testosterone in Microglia Actions and Neuroinflammation}

The CNS is a principally steroidogenic environment to synthesize and metabolize steroids stemming from the circulation. Microglial neuroinflammation can severely affect neurosteroid synthesis, vice versa, steroids can in return mediate microglial neuroinflammation, such as $17 \beta$-E2, testosterone and allopregnanolone [44]. During the development of hippocampus and cortex, the expression of the C-C motif chemokine ligands 20(CCL20) and C-C motif chemokine ligands 4(CCL4) in the developing male hippocampus and cortex are more than 200-fold and 50-fold compared with those of female respectively, which results in the divergent perinatal colonization of brain areas concerned with cognition and memory and plays a role in highly gender divergent hippocampus, amygdala, and cortex. The result suggests that much more sex hormones involved in the development of male brain $[14,45]$. Nowadays, plenty of researches have shown that sexual differentiation and microglia during the brain development play critical roles in neuroinflammation. Microglia increased estradiol production and promoted neuronalsecretion of prostaglandin E2 (PGE2) [19]. Several documents suggested that other inflammatory agents may participate in sex divergence in brains, particularly during the developmental processes.

Meanwhile, studies have also found significant gender divergences in the expression of several inflammatory genes and pro-inflammatory cytokines in the developing POA. In vitro, male and female microglia have shown different inflammatory signaling to LPS and estradiol treatment [46], which argues that in gender differences of brain, microglia may be not only in number or morphology, but may also be phenotypic. Gender differences were appeared in normal neurodevelopment of rodents during several stages, which could affect the dynamically interactions between glia and neurons. Therefore, these stages would be set for both resistance and sensibility to the deterioration of the neurodegenerative diseases in a gender-specific manner [23]. Steroid hormone 
receptors are differently expressed in different sources of microglia, including BV2 and primary microglia isolated from adult mouse brains [47]. Moreover, these receptors are differently distributed in microglia by quantitative and morphological in normal and injured brains. Both estrogens and testosterones exert anti-inflammatory effects on microglia [48].

\section{Estrogen}

Classical Estrogen Receptors and Functions (ER): Estrogens, produced mainly by the ovary, are highly involved in the development of femaleness and maternal functions. Meanwhile, estrogens exert several effects on a large proportion of organs, including brains. Estrogens can go through the BBB and be endogenously produced by the brain relying on its own cholesterol [49]. Estrogens are exposed in females including estrone (E1), estradiol (17- $\beta$-estradiol, E2) and estriol (E3), and E2 is the primary and most effective circulating estrogen. Estrogens and estrogen receptors (ERs) are identified as anti-inflammatory factors in the model of Multiple Sclerosis (MS), which suggested that estrogens and ERs may take part in physiological regulation of neuroinflammation [50]. Functions of estrogens and ERs in brains are extremely complex. ERs possess two classical subtypes: ER type 1(ER1; mainly named as ER $\alpha$ ) and ER type 2 (ER2; mainly named as ER $\beta$ ). Both of them can bind to $17 \beta-\mathrm{E} 2$ and activate estrogen-regulated genes [51,52]. The third ER called G-Protein-Coupled ER (GPER1, commonly named as GPR30) is a membrane ER in several tissues [53,54]. Additionally, several splice variants have been demonstrated, which may be the reason for divergences to estrogens. ERs translocate to the nucleus and bind directly to specific estrogen response element (ERE) sequences on the DNA or to other transcriptional factors to regulate genic expression $[49,55,56]$.

Membrane-bound ER $\alpha$ and ER $\beta$ are also involved in activation of fast-acting signaling pathways. GPR30 could traverse the plasma membrane and trigger rapid signaling cascades [54,57]. Orderly activation of ERs may lead to initially rapid responses followed by genic expression and will regulate the long-term responses [58]. They differ considerably in different cell systems with different structure and function and bind to different estrogenic isomers. The expression of sex steroids receptors on microglia is associated with the phase of brain maturation and microglia are more sensitive to estrogens with older age: the level of ER $\alpha$ mRNA is detectable in microglia purified from mice at postnatal day 3 (P3) and up-regulates in adult mice [59]. The expression of ER $\beta$ from primary microglia can be detected in from P0 newborns but is undetectable starting from P3 until adulthood [47,60]. ERs knock-out mice models have certified that the specific activation of the $E R \alpha$ in the brain is responsible to mediate the neuroprotective effects of estrogens [61]. ER $\beta$, expressed in CD11 $c^{+}$microglia exerts indispensible effects in operating neuroprotection. Once ER $\beta$ was specifically removed from $\mathrm{CD}_{1} 1 \mathrm{c}^{+}$microglia during experimental autoimmune encephalomyelitis (EAE), the neuroprotection of ER $\beta$ ligand treatment was lost [62].

Non-Classical Estrogen Receptors and Functions (GPR30): The GPR30, a receptor binding 17 $\beta$-E2 with high affinity, is recognized to play necessary roles in brain dysfunction. Mechanisms of specific activation to the GPR30 by $17 \beta$-E2 has been demonstrated [63]. GPR30 distributes extensively and covers almost all brain regions [64]. Through using polyclonal antibodies to defense against the human C-terminus of GPR30, researchers revealed an analogous spatial pattern in brains of rats [64], mice [65] and humans $[66,67]$. The immunoreactivity and mRNA expression of GPR30 were remarkable in forebrain of rats, such as hippocampi, frontal cortexes, medial septumes, diagonal band of brocas, nucleus basalis magnocellularises and the striatumes $[63,68]$.

Specific ERs of Microglia in Anti-Neuroinflammatory Responses: Lots of evidences testify the importance of estrogens in neurodegenerative diseases. Nevertheless, there is an uninterrupted controversy concerning whether ERs or GPR 30 takes the beneficial effects on microglia. On the one hand, early studies indicated that $\mathrm{ER} \alpha$ is a primary target for estradiol to produce anti-inflammatory effects in the brain [69]. Transcription factors can activate ER $\alpha$ acting as a ligand, but this activation is ligand independent. So far, little is known about neuroinflammatory signaling of microglia mediated by $\mathrm{ER} \alpha$ in neurodegeneration. An experiment demonstrated that $E R \alpha$ expressed in neuron takes part in the neuropretective effects of estrogen [70]. In addition, ER $\alpha$ mediated immune response and microglial activation, which happened in the brains of women who are estrogen deficient or estrogen aging [71].

On the other hand, it is not ER $\alpha$ but ER $\beta$ predominately expressed in microglia.What's more, ER $\beta$-selective agonists could ameliorate some experimental immune diseases by means of regulation to $\mathrm{T}$ cells and microglia [72]. Moreover, 5-androsten$3 \beta$ and $17 \beta$-E2 synthesized by microglia showed that reduction of ADIOL or ER $\beta$ expression resulted in exaggerated inflammatory responses to toll-like receptor 4 (TLR4) agonists. And the murine BV2 microglia cell line selectively expresses ER $\beta$. These results provided evidence that an ADIOL/ER $\beta /$ CtBP-transrepression pathway mediates inflammatory responses in microglia and can be selectively targeted by ER $\beta$ modulators by controlling the inflammatiory magnitude and duration in microglia and astrocytes $[73,74]$. GPR-30 was also detected in primary microglia purified from rat brains. Moreover, researchers have revealed that GPR-30 agonist could obviously inhibit the accumulation of microglia [75].

Effects of Estrogen on Microglial Activation: The changes of sex steroid, such as estrogen in females and testosterone in males, are associated with an increasing risk of neurodegenerative diseases [58]. The postmenopausal women have a significantly decreasing risk of $\mathrm{AD}$ by applying hormone replacement therapy 
(HRT), accompanied by the decline in number of phagocytic microglia [76]. Furthermore, ovariectomy(OVX) decrease ER $\alpha$ level that deteriorate brain damage, and exacerbatepost-stroke inflammation. To be more specific, OVX can enhance angiotensin and NADPH-oxidase activity, as well as increase the expression of neuroinflammatory markers. But these effects are changed by estrogens. During that process ER $\alpha$ and the brain renin-angiotensin system play a major role [77]. Estrogens exert anti-inflammatory and neuroprotective effects in the central nervous system. Studies revealed that microglia can express subsets of classical, nonclassical ERs and progesterone receptors in a dynamic way [78]. Microglia are involved in ER $\alpha$-induced regulation of local renin angiotensin system (RAS) $[58,77]$. These facts could indicate that estrogens generally enhance the immune system.

Therefore, among sex steroids, estrogens have been received the most attention in preclinical and clinical investigation [79]. Microglia has no ER $\alpha$ in the POA, an important brain area for sexual behavior, and is featured by prominent neuroanatomical gender differences [27]. Exogenous estrogens have immune-enhancing effects on humoral immunity and may mediate cell-mediated immunity at different dose. However, exogenous testosterone can simultaneously depress both humoral and cell-mediated immunity and increase sensibility to bacterial and viral infections [80]. When activated primary microglia were treated with $17 \beta$-estradiol, inducible nitricoxide synthase (iNOS) and reactive oxygen species (ROS) were declined $[75,81,82]$. It has been shown that estrogens could produce anti-oxidant and anti-inflammatory effects by activating endogenous inflammatory signaling, such as phosphatidylinositol 3-kinase /protein kinase B (PI3K) [83] /nuclear factor (erythroid-derived 2)-like 2 (Nrf2) and peroxisome proliferator-activated receptor- $\gamma($ PPAR- $\gamma)[84,85]$. Furthermore, a wealth of experimental models indicated that deficit in endogenous estrogens facilitates the onset of inflammation, and these inflammation reactions could be antagonized by estrogen replacement.

In many inflammatory models, estrogens clearly opposes the inflammatory process by blocking the synthesis of proinflammatory mediators, hematopoietic growth factors and cell differentiation agents [61]. Estrogens can decrease the production of inflammatory cytokines through intervening TLR signaling pathways associated with AP-1 and NF- $\kappa$ B. Evidences showed that NF- $\kappa$ B p 65 is damaged by estrogens through a non-genomic pathway. ER $\alpha$ can inhibit $N F-\kappa B$ activity by the induction of $I \kappa B \alpha$, an inhibiter of NF- $\kappa B$. Equally, AP-1 is associated with effects of estrogens, for which the p85 PI3K signaling pathway is related to estrogen-dependent blocking of TLR4 signal pathway [47] (Figure 2). In the presence of inflammatory responses, estrogen regulates cytokine expression at basal levels through microglia [86], while testosterone and androgen have an inhibitory effect on glial activation [87].
However, how these sex steroids specially alter the microglial activity leading to gender divergence of the brain is still not understood $[79,80]$. Testosterone is converted to $17 \beta-\mathrm{E} 2$ by aromatization in neurons, and after that process, testosterone can exert its reproductive capacity via ERs. Both male and female brains of fetus are exposed environment with high levels of estrogens produced by placentas and mothers. Nevertheless, in female fetus, $\alpha$-fetoproteins bind estrogen and act as carriers, which protects fetal brains from virilising effects of estrogens by stopping estrogens to entry into cells $[88,89]$. Surprisingly, fetal and postnatal microglia are strongly associated with this process through mediating the release of sex steroids especially in the POA, which results in microglial activation and affects fetal brain programming in a gender-dimorph manner [19].

Testosterone and Progesterone: A study found progesterone has therapeutic effects on microglia activation and neuroinflammation. Progesterone therapy deceased neurological behavioral deficits. In addition, progesterone therapy reduces the mRNA expression levels of M1-markers in corpus callosum regions, while the expression of M2-markers was significantly increased, such as triggering receptor expressed on myeloid cells (TREM2) , CD206, Arg-1 and TGF- $\beta$. Furthermore, progesterone therapy significantly decreases the mRNA and protein expression levels of NACHT-, LRP- and pyrin (PYD)-domain-containing protein 3 (NLRP3) and IL-18 ( 2 fold) [90], and it is plausible that progesterone could act on other inflammasomes regulation at the microglial level, such as NACHT-,LRP- and pyrin (PYD)-domaincontaining protein 1 (NLRP1), absent in melanoma2 (AIM2)and NOD-like receptor family apoptosis inhibitory protein (NAIPNLRC4).

Data showed that supplementation of testosterones in castrated male mice restored tight junction integrity, the BBB selective permeability and the inflammatory features was almost abolished, such as iNOS, cyclooxygenase 2 (COX-2), interleukin 1 beta (IL-1 $\beta$ ) and TNF- $\alpha$ [91-98]. During embryogenesis in humans and neonatally in rodents, production of testosterone is responsible for the masculinization of selected brain circuits which control sexually divergent behaviors and physiological processes. In line with these evidences, microglial gender divergences in number and morphology appear not until testosterones soar at P4 when more morphology-activated microglia in male rats. That pattern was shifted until $\mathrm{P}$ [30], which is previous to the onset of adult circulating hormones [14]. Although progesterone receptor (PR) and androgen receptor (AR) are not discovered in adult microglia, data show that developing microglia express both $\mathrm{PR}$ and $\mathrm{AR}$, which results in microglia respond to the surge in testosterone and adjust microglia into a male-specific pattern of maturation [59] (Tables 1-3)(Figure 2). 


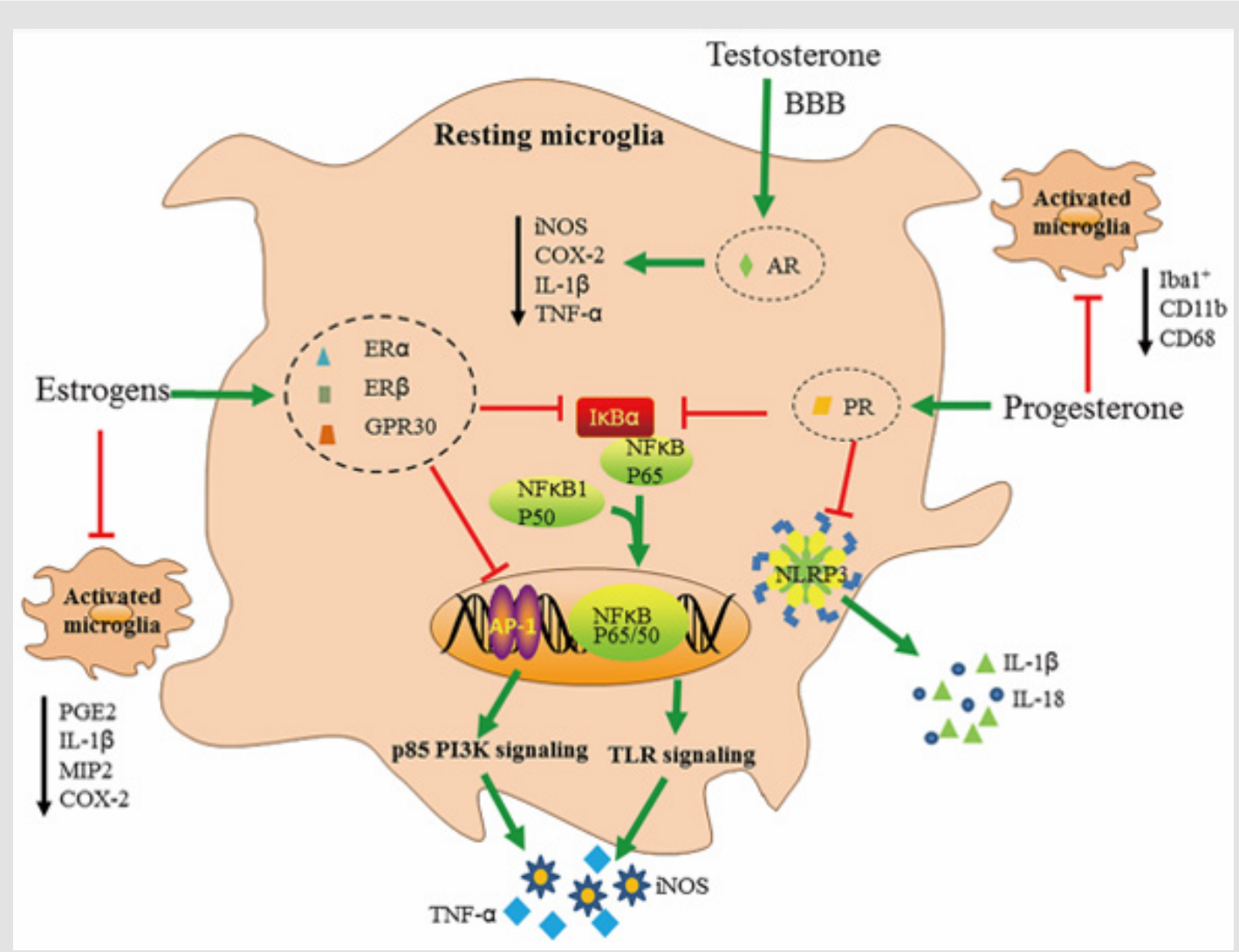

Figure 2: The anti-inflammatory effects of estrogens, testosterone and progesterone on microglia, Firstly, estrogens take antiinflammatory effects by combining with their receptors (ERa, ER $\beta$ and GPR30). They inhibit the production of in cytokines by interfering with TLR signaling through NF-kB and AP- I. ERa inhibits NF-kB activity by inducing the synthesis of its inhibitory protein-IkBa. Similarly, AP-1 is involved in the actions of estrogen by p85 PI3K signaling. Estrogens also inhibit the activation of microglia. Secondly, progesterone and its receptor PR could inhibit NF-kB and NLRP3 inflammasome activity resulting in lower reduction of IL-1 $\beta$, IL-18, COX-2, and PGE2, Lastly, testosterone holds the BBB selective permeability, tight junction integrity and almost completely abrogated the inflammatory features, such as iNOS, COX-2, 1L-1 $\beta$ and TNF-a.

Table 1: Neuroinflammation presents sexual dimorphism in different models of Alzheimer's disease.

\begin{tabular}{|c|c|c|c|}
\hline Model & Exposure & Effects & Reference \\
\hline $\mathrm{AD}$ patients & & $\begin{array}{l}\text { Female AD patients had higher levels of CHI3L in cerebellums } \\
\text { than males. }\end{array}$ & [92] \\
\hline Tg CRND mice & $\begin{array}{l}2 \text { months old of postnatal age } \\
\text { (P60) }\end{array}$ & $\begin{array}{c}\text { Neuroinflammation was more prominent in females at later } \\
\text { disease stages. }\end{array}$ & {$[43]$} \\
\hline C57BL6 mice & 3,12 and 24 months old & $\begin{array}{l}\text { Inflammatory genes were enhanced in females compared with } \\
\text { age-matched males, and aging-associated genes highly spread } \\
\text { for microglia-specific transcripts. }\end{array}$ & [93] \\
\hline Tg 2576 mice & 6 and 14 months old & $\begin{array}{l}\text { Oligomeric and monomeric } \mathrm{A} \beta \text { were decreased in female hippo- } \\
\text { campi but increased in males when mt } 1 \text { was overexpression. }\end{array}$ & [94] \\
\hline APP/PS1 mice & 16 months old & TSPO was significantly higher in female mice. & [95] \\
\hline LPS-induced APP/PS1 mice & $\begin{array}{l}\text { 4.5-month-old mice were treated } \\
\text { with } 100 \mu \mathrm{g} / \mathrm{kg} \text { LPS }\end{array}$ & Female hippocampi were more tolerant to acute inflammation. & [96] \\
\hline $\begin{array}{l}\text { APP/PS1/tau triple-transgenic } \\
\text { mice }\end{array}$ & 12 months old & $\begin{array}{l}\text { Female mice displayed more prominent neuroinflammation } \\
\text { than male } 3 \mathrm{x} \text { Tg mice. }\end{array}$ & [97] \\
\hline $\begin{array}{l}\text { Primary male and female } \\
\text { microglia }\end{array}$ & $\begin{array}{l}\text { From forebrains of wistar rat's } \\
\text { newborn to } 2 \text { days, and stimulated } \\
\text { by } 20 \mathrm{ng} / \mathrm{mL} \text { TFN- } \gamma \text { for } 24 \text { hours }\end{array}$ & $\begin{array}{l}\text { Male microglia showed higher migration, but female microglia } \\
\text { showed higher basal and stimulated phagocytic activity. }\end{array}$ & [41] \\
\hline
\end{tabular}

Abbreviations: CHI3L: Chitinase-3-Like 1 Protein; A $\beta$ : Amyloid- $\beta$; TSPO: Translocator Protein of 18 kDa; LPS: lipopolysaccharide; TFN-y: Interferon-g; MT-1: Metallothionein-1. 
Table 2: Effects of estrogens and progestogens on neuroinflammation in different models of Alzheimer's disease.

\begin{tabular}{|c|c|c|c|c|}
\hline Sex Hormone & Model & Exposure & Effects & Reference \\
\hline & APP23 mice & Ovariectomy & $\begin{array}{l}\text { Pathological signs of AD and microglial } \\
\text { activation were increased. }\end{array}$ & \multirow{8}{*}[98]{} \\
\hline & ICR rats & Ovariectomied when 9 months old & $\begin{array}{l}\text { Microgliosis and astrogliosis and NF- } \mathrm{kB} \\
\text { activation were increased. }\end{array}$ & \\
\hline & SD rats & $\begin{array}{c}\text { OVX, } 10-15 \mathrm{pg} / \mathrm{mL} 17 \beta \text {-estradiol in mini-pumps }(0.5 \mu \mathrm{L} / \\
\text { hour, } 14 \text {-day release) }\end{array}$ & $\begin{array}{l}\text { NLRP3 inflammasome formation was } \\
\text { negatively regulated. }\end{array}$ & \\
\hline & BV2 cells & $\mathrm{A} \beta_{1-42}(1 \mu \mathrm{M})$ and $\beta$-estradiol $(10 \mu \mathrm{M})$ for 24 hours & $\begin{array}{c}\text { Microglial inflammatory responses were } \\
\text { decreased. }\end{array}$ & \\
\hline Estrogens & BV2 cells & $\begin{array}{c}\text { Hypoxic stimulation for } 3 \text { hours and treated with } \\
17 \beta \text {-estradiol }(27.24 \mathrm{ng} / \mathrm{mL})\end{array}$ & $\begin{array}{l}\text { NLRP3 inflammasome formation was } \\
\text { negatively regulated. }\end{array}$ & \\
\hline \multirow{3}{*}{ Progestogens } & SD rats & $\begin{array}{l}\mathrm{A} \beta_{25-35}(2 \mathrm{~g} / \mathrm{L}) \text { injected into the bilateral hippocampus CA1 } \\
\text { region and treated with progestogens }(4 \mathrm{mg} / \mathrm{kg}, 8 \mathrm{mg} / \mathrm{kg} \\
\text { and } 16 \mathrm{mg} / \mathrm{kg})\end{array}$ & $\begin{array}{l}\text { expressions of TNF and IL-1 } \beta \text { were de- } \\
\text { creased in a dose-dependent manner. }\end{array}$ & \\
\hline & 3xTg mice & $\begin{array}{c}\text { allopregnanolone }(10 \mathrm{mg} / \mathrm{kg}) \text { respectively for } 1 / \mathrm{month} 1 / \\
\text { week/6 months, and } 3 / \text { week/ } 3 \text { months regimens single } \\
\text { injection }\end{array}$ & $\begin{array}{l}\text { Administration of allopregnanolone } \\
\text { decreased microglial activation. }\end{array}$ & \\
\hline & BV2 cells & $\begin{array}{l}\text { Hypoxic stimulation for } 3 \text { hours and treated with progesto- } \\
\text { gens }(31.45 \mathrm{ng} / \mathrm{mL})\end{array}$ & $\begin{array}{l}\text { Inflammasome activation in microglia } \\
\text { was dampened. }\end{array}$ & \\
\hline
\end{tabular}

Table 3: Effects of estrogens and progestogens on neuroinflammation in different models of Parkinson disease.

\begin{tabular}{|c|c|c|c|c|}
\hline Sex Hormone & Model & Exposure & Effects & Reference \\
\hline \multirow{8}{*}{ Estrogens } & AD patients & Recruited from the Swedish population & $\begin{array}{l}\text { ER } \beta \text { genes polymorphismcorrelate with } \\
\text { early age disease onset. }\end{array}$ & \multirow{9}{*}{ [98] } \\
\hline & human & & $\begin{array}{l}\text { Women suffering unilateral or bilateral } \\
\text { ovariectomy before the onset of meno- } \\
\text { pause showed higher risks of PD. }\end{array}$ & \\
\hline & wistar rats & OVX & $\begin{array}{l}\text { Microglial activation is increased, while } \\
\text { expression of microglia-mediated genes } \\
\text { is downregulated. }\end{array}$ & \\
\hline & C57BL/6N mice & $\begin{array}{l}\text { Ovariectomized when } 10 \text { weeks old and were } \\
\text { given } 17 \beta-\mathrm{E} 0.01 \mathrm{mg} / \text { day }\end{array}$ & $\begin{array}{c}\text { 6-OHDA and MPTP -induced ovariec- } \\
\text { tomized mice present heavier neuronal } \\
\text { damage and stronger microgliosis } \\
\text { compared. }\end{array}$ & \\
\hline & C57BL mice & female mice was induced by MPTP & $\begin{array}{l}\text { Male mice presented faster iNOS and } \\
\text { more dopamine after MPTP treatment } \\
\text { compared to females. }\end{array}$ & \\
\hline & $\begin{array}{l}\text { C57BL/6 mice; BV2 } \\
\text { cells }\end{array}$ & $\begin{array}{l}\text { MPTP-induced mice were given } 5 \mu \mathrm{g} \text { G1and } 10 \\
\mu \mathrm{g} \text { G15 twice/day for } 12 \text { days; } 100 \mu \mathrm{M} \text { MPP was } \\
\text { treated to BV2 with } \mathrm{G} 1(1,10 \text {, and } 100 \mathrm{nM}) \text { or } \\
\text { G15 (100 nM) for } 24 \mathrm{~h}\end{array}$ & $\begin{array}{l}\text { G1 inhabited microglial activation and } \\
\text { increased dopaminergic neuronal cell } \\
\text { survival in male MPTP-treated mice. }\end{array}$ & \\
\hline & $\begin{array}{l}\text { WT, ER } \alpha \mathrm{KO} \text {, and } \\
\text { ER } \beta \mathrm{KO} \text { female mice }\end{array}$ & $\begin{array}{l}\text { Ovariectomized when } 10-15 \text { weeks, } 7 \text { days after } \\
\text { OVX, all mice received injection of LPS }(5 \mathrm{mg} / \mathrm{kg}) \\
\text { and treated with } 180 \mu \mathrm{g} / \mathrm{mL} \mathrm{E2}\end{array}$ & $\begin{array}{l}17 \beta-E 2 \text { reduced proinflammatory cyto- } \\
\text { kines (IL-1, TNF, IL-6, IL-12 p40) and the } \\
\text { chemokine rantes in the female brains. }\end{array}$ & \\
\hline & $\begin{array}{l}\text { Primary microglia from } \\
\text { 1-2-day-old Wistar } \\
\text { rats; and SH-SY5Y cell }\end{array}$ & $\begin{array}{l}\text { Microglia were pretreated with Tam or Rlx and } \\
\text { then treated with } 10 \mathrm{ng} / \mathrm{mL} \text { LPS for } 6 \mathrm{~h} \text {; SH-SY5Y } \\
\text { were pretreated with Tam or Rlx for } 24 \mathrm{~h} \text { and } \\
\text { then treated with } 10 \mathrm{ng} / \mathrm{mL} \text { LPS for } 24 \mathrm{~h} .\end{array}$ & $\begin{array}{c}\text { SERMs can suppress production of } \\
\text { proinflammatory cytokines and chemok- } \\
\text { ines, such as TNF- } \alpha \text {, IL-1 } \beta, \text { MCP1 or MIP2 } \\
\text { in microglia }\end{array}$ & \\
\hline Progestogens & BV-2 & $\begin{array}{l}\text { BV2 were pretreated with progesterone for } 1 \mathrm{~h} \text {, } \\
\text { then treated with } 10 \mathrm{ng} / \mathrm{mL} \text { LPS for } 4 \mathrm{~h} \text {. }\end{array}$ & $\begin{array}{l}\text { NF- } \kappa \mathrm{B} \text { and JNK pathways, as well as } \\
\text { TNF and iNOS production were inhabit- } \\
\text { ed by progesterone. }\end{array}$ & \\
\hline
\end{tabular}

Abbreviations: OVX: Ovariectomized; MPTP: 1-Methyl-4-Phenyl-1,2,3,6-Tetrahydropyridine; SERMs: Selective Estrogen Receptor Modulators; MCP1: Monocyte Chemotactic Protein-1; MIP2: Macrophage Inflammationprotein-2; GFAP : Glial Fibrillary Acidic Protein 


\section{Directions}

Since neurodegenerative diseases were first described more than 100 years ago, almost all of focuses were laid on the gross anatomical changes, such as excessive tau phosphorylation, superabundant protein aggregation and outnumbered neuron loss. Nevertheless, more and more mechanistic, genetic, and histopathological documents point to inflammation-related changes such inflammatory cytokines, immune cell proliferation and migration of inflammatory cells, highly dynamic phagocytosis, and reactive gliosis as general characteristics of neurodegenerative diseases, such as TREM2, inflammasomes and inflammatory complement cascades [99-101], which were long recognized as secondary or reactive responses to latent processes. Meanwhile, recently emerging evidences also start to break through the stereotypes and identify the immune system as the central player in disease occurrence and deterioration, and new functional aspects of these inflammatory signaling pathways are highlighted [102]. For example, Nlrp3 knock-out APP/PS1 transgenic mice presented fewer inflammatory cytokines and phosphorylated tau protein, as well as amyloid deposits.

A risk genes analysis about PD pathway founds prominent pregnancy in several adaptive immune cells and immune signaling pathways. Pathogenic types of $\alpha$-synuclein could induce immune responses in $\mathrm{T}$ cells which were purified from Parkinson's patients $[103,104]$. Sex differences in neurodegenerative diseases mainly exist in microglia, which play indispensible role in neuroinflammation. Nowadays, neuroinflammation is becoming the focus of neurodegeneration. Surprisingly, $A \beta$ might be a neuroprotective hero in the onset of neurodegenerative diseases, and infectious or sterile inflammatory stimulus might impulse amyloidsis [105]. Glial cells exert as important participants to the development and homeostasis of the central nervous system. Especially, microglia play the major role as the crossroad binding the immune reaction and the nervous system, each of which is extremely critical for the owner to percept external and internal environments16. In conclusion, it may be a promising research direction to explore the neuroinflammation, immune-mediated mechanisms and the application of immunomodulation. Antiinflammation in the brain and immune-modification strategy aiming at male and female in the way of precision medicine would be renewing and spark cure to neurodegenerative disorders.

\section{Consent for Publication}

Not applicable.

\section{Funding}

None.

\section{Conflict of Interest}

The authors declare no conflict of interest, financial or otherwise.

\section{Acknowledgement}

The authors are grateful for the Shijingshan's Tutor Studio of Pharmacology, Guizhou Province [GZS-2016(07)].

\section{References}

1. Dugger BN, Dickson DW (2017) Pathology of Neurodegenerative Diseases. Cold Spring Harb Perspect Biol 9(7).

2. Ransohoff RM (2016) How neuroinflammation contributes to neurodegeneration. Science 353(6301): 777-783.

3. Ouchi Y (2017) Imaging neuroinflammation to monitor alphasynucleinopathy. Lancet Neurol 16(10): 763-764.

4. Sekiya M, Wang M, Fujisaki N, Sakakibara Y, Quan X, et al. (2018) Integrated biology approach reveals molecular and pathological interactions among Alzheimer's Abeta42, Tau, TREM2, and TYROBP in Drosophila models. Genome Med 10(1): 26.

5. Wong YC, Krainc D (2017) Alpha-synuclein toxicity in neurodegeneration: mechanism and therapeutic strategies. Nat Med 23(2): 1-13.

6. Ising C, Carmen Venegas, Shuangshuang Zhang, Hannah Scheiblich, Susanne V Schmidt, et al. (2019) NLRP3 inflammasome activation drives tau pathology. Nature 575: 669-673.

7. Focke C, Blume T, Zott B, Shi Y, Deussing M, et al. (2019) Early and Longitudinal Microglial Activation but Not Amyloid Accumulation Predicts Cognitive Outcome in PS2APP Mice. J Nucl Med 60(4): 548-554.

8. May M (2016) Sex on the brain: Unraveling the differences between women and men in neurodegenerative disease. Nat Med 22: 1370-1372.

9. Pike CJ (2017) Sex and the development of Alzheimer's disease. J Neurosci Res 95(1-2): 671-680.

10. Kang SS, Ebbert MTW, Baker KE, Cook C, Wang X, et al. (2018) Microglial translational profiling reveals a convergent APOE pathway from aging, amyloid, and tau. J Exp Med 215(9): 2235-2245.

11. Lee J, Paulo Pinares Garcia, Hannah Loke, Seungmin Ham, Eric Vilain, et al. (2019) Sex-specific neuroprotection by inhibition of the Y-chromosome gene, SRY, in experimental Parkinson's disease. Proc Natl Acad Sci USA 116(33): 16577-16582.

12. Vegeto E, Villa A, Della Torre S, Crippa V, Rusmini P, et al. (2019) The role of sex and sex Hormones in Neurodegenerative Diseases. Endocr Rev.

13. Schwarz JM, Sholar PW, Bilbo SD (2012) Sex differences in microglial colonization of the developing rat brain. J Neurochem 120(6): 948-963.

14. Bourque M, Dluzen DE, Di Paolo T (2009) Neuroprotective actions of sex steroids in Parkinson's disease. Front Neuroendocrinol 30(2): 142-157.

15. VanRyzin JW, Pickett LA, Mc Carthy MM (2018) Microglia: Driving critical periods and sexual differentiation of the brain. Dev Neurobiol 78(6): 580-592.

16. Thion MS, Ginhoux F, Garel S (2018) Microglia and early brain development: An intimate journey. Science 362(6411): 185-189.

17. Salter MW, Stevens B (2017) Microglia emerge as central players in brain disease. Nat Med 23(9): 1018-1027.

18. Abbott A (2018) Is 'friendly fire' in the brain provoking Alzheimer's disease? Nature 556: 426-428.

19. Lenz KM, Mc Carthy MM (2015) A starring role for microglia in brain sex differences. Neuroscientist 21(3): 306-321.

20. Villa A, Della Torre S, Maggi A (2019) Sexual differentiation of microglia. Front Neuroendocrinol 52: 156-164.

21. Hanamsagar R, Alter MD, Block CS, Sullivan H, Bolton JL, et al. (2017) Generation of a microglial developmental index in mice and in humans reveals a sex difference in maturation and immune reactivity. Glia 65(9): 1504-1520. 
22. Villa A, Gelosa P, Castiglioni L, Cimino M, Rizzi N, et al. (2018) Sex-Specific Features of Microglia from Adult Mice. Cell Rep 23(12): 3501-3511.

23. Hanamsagar R, Alter MD, Block CS, Sullivan H, Bolton JL, et al. (2017) Generation of a microglial developmental index in mice and in humans reveals a sex difference in maturation and immune reactivity. Glia 65(9): 1504-1520.

24. Thion MS, Low D, Silvin A, Chen J, Grisel P, et al. (2018) Microbiome Influences Prenatal and Adult Microglia in a Sex-Specific Manner. Cell 172(3): 500-516.

25. Guneykaya D, Ivanov A, Hernandez DP, Haage V, Wojtas B, et al. (2018) Transcriptional and Translational Differences of Microglia from Male and Female Brains. Cell Rep 24(10): 2773-2783.

26. Caplan HW, Cox CS, Bedi SS (2017) Do microglia play a role in sex differences in TBI? J Neurosci Res 95(1-2): 509-517.

27. Lenz K M, Nugent BM, Haliyur R, McCarthy MM (2013) Microglia are essential to masculinization of brain and behavior. J Neurosci 33(7): 2761-2772

28. McCarthy MM, Pickett LA, VanRyzin JW, Kight KE (2015) Surprising origins of sex differences in the brain. Horm Behav 76: 3-10.

29. Mouton PR, Long JM, Lei DL, Howard V, Jucker M, et al. (2002) Age and gender effects on microglia and astrocyte numbers in brains of mice. Brain Res 956(1): 30-35.

30. Schwarz JM, Bilbo SD (2012) Sex, glia, and development: interactions in health and disease. Horm Behav 62(3): 243-253

31. Rahimian R, Cordeau P, Kriz J (2019) Brain Response to Injuries: When Microglia Go Sexist. Neuroscience 405: 14-23.

32. Prince M, Bryce R, Albanese E, Wimo A, Ribeiro W, et al. (2013) The global prevalence of dementia: a systematic review and metaanalysis. Alzheimers Dement 9(1): 63-75.

33. Jia J, Wei C, Chen S, Li F, Tang Y, et al. (2018) The cost of Alzheimer's disease in China and re-estimation of costs worldwide. Alzheimers Dement 14(4): 483-491.

34. Weinhard L, Neniskyte U, Vadisiute A, di Bartolomei G, Aygün N, et al. (2018) Sexual dimorphism of microglia and synapses during mouse postnatal development. Dev Neurobiol 78(8): 618-626.

35. Martin Prince AW, Maëlenn Guerchet, Gemma Claire Ali, Yu Tzu Wu, Matthew Prina (2015) World Alzheimer Report 2015.

36. Ferretti MT, Iulita MF, Cavedo E, Chiesa PA, Schumacher Dimech A, et al. (2018) Sex differences in Alzheimer disease - the gateway to precision medicine. Nat Rev Neurol 14(8): 457-469.

37. Hebert LE, Scherr PA, McCann JJ, Beckett LA, Evans DA (2001) Is the risk of developing Alzheimer's disease greater for women than for men? Am J Epidemiol 153(2): 132-136.

38. Oveisgharan S, Arvanitakis Z, Yu L, Farfel J, Schneider JA, et al. (2018) Sex differences in Alzheimer's disease and common neuropathologies of aging. Acta Neuropathol 136(6): 887-900.

39. Bright F, Werry EL, Dobson Stone C, Piguet O, Ittner LM, et al. (20119) Neuroinflammation in frontotemporal dementia. Nat Rev Neurol 15(Suppl 1): 1.

40. Curtis AF, Masellis M, Hsiung GR, Moineddin R, Zhang K, et al. (2017) Sex differences in the prevalence of genetic mutations in FTD and ALS: A meta-analysis. Neurology 89(15): 1633-1642.

41. Yanguas Casás N, Crespo Castrillo A, de Ceballos ML, Chowen JA, Azcoitia I, et al. (2018) Sex differences in the phagocytic and migratory activity of microglia and their impairment by palmitic acid. Glia 66(3): 522-537.

42. Sadagurski M, Cady G, Miller RA (2017) Anti-aging drugs reduce hypothalamic inflammation in a sex-specific manner. Aging Cell 16(4): 652-660.
43. Keyvani K, Münster Y, Kurapati NK, Rubach S, Schönborn A, et al. (2018) Higher levels of kallikrein-8 in female brain may increase the risk for Alzheimer's disease. Brain Pathol 28(6): 947-964.

44. Yilmaz C, Karali K, Fodelianaki G, Gravanis A, Chavakis T, et al. (2019) Neurosteroids as regulators of neuroinflammation. Front Neuroendocrinol 55: 100788.

45. Lenz KM, Nugent BM, McCarthy MM (2012) Sexual differentiation of the rodent brain: dogma and beyond. Front Neurosci 6: 26 .

46. Loram LC, Sholar PW, Taylor FR, Wiesler JL, Babb JA, et al. (2012) Sex and estradiol influence glial pro-inflammatory responses to lipopolysaccharide in rats. Psychoneuroendocrinology 37(10): 16881699.

47. Villa A, Vegeto E, Poletti A, Maggi A (2016) Estrogens, Neuroinflammation, and Neurodegeneration. Endocr Rev 37(4): 372-402.

48. Kodama L, Gan L (2019) Do Microglial Sex Differences Contribute to Sex Differences in Neurodegenerative Diseases? Trends Mol Med 25(9): 741-749.

49. Rettberg JR, Yao J, Brinton RD (2014) Estrogen: A master regulator of bioenergetic systems in the brain and body. Front Neuroendocrinol 35(1): 8-30.

50. Gold SM, Voskuhl RR (2009) Estrogen treatment in multiple sclerosis. J Neurol Sci 286(1-2): 99-103.

51. Kuiper GG, Enmark E, Pelto Huikko M, Nilsson S, Gustafsson JA (1996) Cloning of a novel receptor expressed in rat prostate and ovary. Proc Natl Acad Sci USA 93(12): 5925-5930.

52. Chang EC, Charn TH, Park SH, Helferich WG, Komm B, et al. (2008) Estrogen Receptors alpha and beta as determinants of gene expression: influence of ligand, dose, and chromatin binding. Mol Endocrinol 22(5): 1032-1043.

53. Funakoshi T, Yanai A, Shinoda K, Kawano MM, Mizukami Y (2006) G protein-coupled receptor 30 is an estrogen receptor in the plasma membrane. Biochem Biophys Res Commun 346(3): 904-910.

54. Prossnitz ER, Barton M (2011) The G-protein-coupled estrogen receptor GPER in health and disease. Nat Rev Endocrinol 7(12): 715-726.

55. Nilsson S, Koehler KF, Gustafsson JA (2011) Development of subtypeselective oestrogen receptor-based therapeutics. Nat Rev Drug Discov 10: 778-792.

56. Brinton RD, Yao J, Yin F, Mack WJ, Cadenas E (2015) Perimenopause as a neurological transition state. Nat Rev Endocrinol 11(7): 393-405.

57. Levin ER (2014) Extranuclear estrogen receptor's roles in physiology: lessons from mouse models. Am J Physiol Endocrinol Metab307(2): E133-140.

58. Labandeira Garcia JL, Rodriguez Perez AI, Valenzuela R, Costa Besada MA, Guerra MJ (2016) Menopause and Parkinson's disease. Interaction between estrogens and brain renin-angiotensin system in dopaminergic degeneration. Front Neuroendocrinol 43: 44-59.

59. Sierra A, Gottfried Blackmore A, Milner TA, McEwen BS, Bulloch K (2008) Steroid hormone receptor expression and function in microglia. Glia 56(6): 659-674.

60. Morale MC, Serra PA, L'episcopo F, Tirolo C, Caniglia S, et al. (2006) Estrogen, neuroinflammation and neuroprotection in Parkinson's disease: glia dictates resistance versus vulnerability to neurodegeneration. Neuroscience 138(3): 869-878.

61. Vegeto E, Ciana P, Maggi A (2002) Estrogen and inflammation: hormone generous action spreads to the brain. Mol Psychiatry 7(3): 236-238.

62. Kim RY, Mangu D, Hoffman AS, Kavosh R, Jung E, et al. (2018) Oestrogen receptor \&beta; ligand acts on CD11c\&plus; cells to mediate protection in experimental autoimmune encephalomyelitis. Brain 141(1): 132-147. 
63. Hadjimarkou MM, Vasudevan N (2018) GPER1/GPR30 in the brain: Crosstalk with classical estrogen receptors and implications for behavior. J Steroid Biochem Mol Biol 176: 57-64.

64. Brailoiu E, Dun SL, Brailoiu GC, Mizuo K, Sklar LA, et al. (2007) Distribution and characterization of estrogen receptor $\mathrm{G}$ protein-coupled receptor 30 in the rat central nervous system. J Endocrinol 193(2): 311-321.

65. Hazell GG, Yao ST, Roper JA, Prossnitz ER, O'Carroll AM, et al. (2009) Localisation of GPR30, a novel G protein-coupled oestrogen receptor, suggests multiple functions in rodent brain and peripheral tissues. J Endocrinol 202(8): 223-236.

66. Owman C, Nilsson C, Lolait SJ (1996) Cloning of cDNA encoding a putative chemoattractant receptor. Genomics 37(2): 187-194.

67. O’Dowd BF, Nguyen T, Marchese A, Cheng R, Lynch KR, et al. (1998) Discovery of three novel G-protein-coupled receptor genes. Genomics 47(2): 310-313.

68. Hammond R, Nelson D, Gibbs RB (2011) GPR30 co-localizes with cholinergic neurons in the basal forebrain and enhances potassium-stimulated acetylcholine release in the hippocampus. Psychoneuroendocrinology 36(2): 182-192.

69. Vegeto E, Silvia Belcredito, Sabrina Etteri, Serena Ghisletti, Alessia Brusadelli, et al. (2003) Estrogen receptor-alpha mediates the brain antiinflammatory activity of estradiol. Proc Natl Acad Sci U S A 100(16): 9614-9619.

70. Elzer JG, Muhammad S, Wintermantel TM, Regnier Vigouroux A, Ludwig J, et al. (2010) Neuronal estrogen receptor-alpha mediates neuroprotection by 17beta-estradiol. J Cereb Blood Flow Metab 30(5): 935-942.

71. Cordeau P, Lalancette Hébert M, Weng YC, Kriz J (2016) Estrogen receptors alpha mediates postischemic inflammation in chronically estrogen-deprived mice. Neurobiol Aging 40: 50-60.

72. Wan fu Wu, Xin jie Tan, Yu bing Dai, Venkatesh Krishnan, Margaret Warner, et al. (2013) Targeting estrogen receptor beta in microglia and $\mathrm{T}$ cells to treat experimental autoimmune encephalomyelitis. Proc Natl Acad Sci U S A 110(9): 3543-3548.

73. Saijo K, Collier JG, Li AC, Katzenellenbogen JA, Glass CK (2011) An ADIOL-ERbeta-CtBP transrepression pathway negatively regulates microglia-mediated inflammation. Cell 145(4): 584-595.

74. Wood H (2011) Neuroimmunology: estrogen receptor ligands suppress inflammatory responses in astrocytes and microglia. Nat Rev Neurol 7(7): 355.

75. Johann S, Beyer C (2013) Neuroprotection by gonadal steroid hormones in acute brain damage requires cooperation with astroglia and microglia. J Steroid Biochem Mol Biol 137: 71-81.

76. McCarrey AC, Resnick SM (2015) Postmenopausal hormone therapy and cognition. Horm Behav 74: 167-172.

77. Lambert JC, Ibrahim Verbaas CA, Harold D, Naj AC, Sims R, et al. (2013) Meta-analysis of 74,046 individuals identifies 11 new susceptibility loci for Alzheimer's disease. Nat Genet 45(12): 1452-1458.

78. Habib P, Beyer C (2015) Regulation of brain microglia by female gonadal steroids. J Steroid Biochem Mol Biol 146: 3-14.

79. Fisher DW, Bennett DA, Dong H (2018) Sexual dimorphism in predisposition to Alzheimer's disease. Neurobiol Aging 70: 308-324.

80. Hanamsagar R, Bilbo SD (2016) Sex differences in neurodevelopmental and neurodegenerative disorders: Focus on microglial function and neuroinflammation during development. J Steroid Biochem Mol Biol 160: 127-133.

81. Bruce Keller AJ, Jonathan L Keeling, Jeffrey N Keller, Feng F Huang, Simonetta Camondola, et al. (2000) Antiinflammatory effects of estrogen on microglial activation. Endocrinology 141(10): 3646-3656.

82. Dimayuga FO, Janelle L Reed, Genevieve A Carnero, Chunmei Wang Edgardo R Dimayuga, et al. (2005) Estrogen and brain inflammation: effects on microglial expression of MHC, costimulatory molecules and cytokines. J Neuroimmunol 161(1-2): 123-136.

83. Sakthivel KM, Guruvayoorappan C (2013) Amentoflavone inhibits iNOS, COX-2 expression and modulates cytokine profile, NF-kappaB signal transduction pathways in rats with ulcerative colitis. Int Immunopharmacol 17(3): 907-916.

84. Wang Y, Huang Y, Xu Y, Ruan W, Wang H, et al. (2018) A Dual AMPK/ Nrf2 Activator Reduces Brain Inflammation After Stroke by Enhancing Microglia M2 Polarization. Antioxid Redox Signal 28(2): 141-163.

85. Bordet R, Ouk T, Petrault O, Gele P, Gautier S, et al. (2006) PPAR: a new pharmacological target for neuroprotection in stroke and neurodegenerative diseases. Biochem Soc Trans 34(6): 1341-1346.

86. Vegeto E, Bonincontro C, Pollio G, Sala A, Viappiani S, et al. (2001) Estrogen prevents the lipopolysaccharide-induced inflammatory response in microglia. J Neurosci 21(6): 1809-1818.

87. Barreto G, Veiga S, Azcoitia I, Garcia Segura LM, Garcia Ovejero D (2007) Testosterone decreases reactive astroglia and reactive microglia after brain injury in male rats: role of its metabolites, oestradiol and dihydrotestosterone. Eur J Neurosci 25(10): 3039-3046.

88. Wilson CA, Davies DC (2007) The control of sexual differentiation of the reproductive system and brain. Reproduction 133(2): 331-359.

89. Karaismailoğlu S, Erdem A (2013) The effects of prenatal sex steroid hormones on sexual differentiation of the brain. J Turk Ger Gynecol Assoc 14(3): 163-167.

90. Aryanpour R, Pasbakhsh P, Zibara K, Namjoo Z, Beigi Boroujeni F, et al. (2017) Progesterone therapy induces an M1 to M2 switch in microglia phenotype and suppresses NLRP3 inflammasome in a cuprizoneinduced demyelination mouse model. Int Immunopharmacol 51: 131139.

91. Atallah A, Mhaouty Kodja S, Grange Messent V (2017) Chronic depletion of gonadal testosterone leads to blood-brain barrier dysfunction and inflammation in male mice. J Cereb Blood Flow Metab 37(9): 3161-3175.

92. Sanfilippo C, Castrogiovanni P, Imbesi R, Kazakowa M, Musumeci G, et al. (2019) Sex difference in CHI3L1 expression levels in human brain aging and in Alzheimer's disease. Brain Res 1720: 146305.

93. Colleen A Mangold, Benjamin Wronowski, Mei Du, Dustin R Masser, Niran Hadad, et al. (2017) Sexually divergent induction of microglial-associated neuroinflammation with hippocampal aging. J Neuroinflammation 14(141).

94. Manso Y, Comes G, López Ramos JC, Belfiore M, Molinero A, et al. (2016) Overexpression of Metallothionein-1 Modulates the Phenotype of the Tg2576 Mouse Model of Alzheimer's Disease. J Alzheimers Dis 51(1): 81-95.

95. Sahlholm K, Liao F, Holtzman DM, Xu J, Mach RH (2015) Sigma-2 receptor binding is decreased in female, but not male, APP/PS1 mice. Biochem Biophys Res Commun 460(2): 439-445.

96. Agostini A, Yuchun D, Li B, Kendall DA, Pardon MC (2020) Sex-specific hippocampal metabolic signatures at the onset of systemic inflammation with lipopolysaccharide in the APPswe/PS1dE9 mouse model of Alzheimer's disease. Brain Behav Immun 83: 87-111.

97. Yang JT, Wang ZJ, Cai HY, Yuan L, Hu MM, et al. (2018) Sex Differences in Neuropathology and Cognitive Behavior in APP/PS1/tau TripleTransgenic Mouse Model of Alzheimer's Disease. Neurosci Bull 34(5): 736-746.

98. Yilmaz C, Karali K, Fodelianaki G, Gravanis A, Chavakis, et al. (2019) Neurosteroids as regulators of neuroinflammation. Front Neuroendocrinol 55: 100788.

99. Hammond TR, Dufort C, Dissing Olesen L, Giera S, Young A, et al. (2019) Single-Cell RNA Sequencing of Microglia throughout the Mouse Lifespan and in the Injured Brain Reveals Complex Cell-State Changes. Immunity 50(1): 253-271. e256. 
100. Mathys H, Adaikkan C, Gao F, Young JZ, Manet E, et al. (2017) Temporal Tracking of Microglia Activation in Neurodegeneration at Single-Cell Resolution. Cell Rep 21(2): 366-380.

101. Keren Shaul H, Spinrad A, Weiner A, Matcovitch Natan O, Dvir Szternfeld $\mathrm{R}$, et al. (2017) A Unique Microglia Type Associated with Restricting Development of Alzheimer's Disease. Cell 169(7): 1276-1290. e1217.

102. Hammond TR, Marsh SE, Stevens B (2019) Immune Signaling in Neurodegeneration. Immunity 50(4): 955-974.

103. Sulzer D, Alcalay RN, Garretti F, Cote L, Kanter E, et al. (2017) Erratum T cells from patients with Parkinson's disease recognize alphasynuclein peptides. Nature 549(7671): 292.

\section{ISSN: 2574-1241}

DOI: $10.26717 /$ BJSTR.2020.25.004160

Jing Shan Shi. Biomed J Sci \& Tech Res

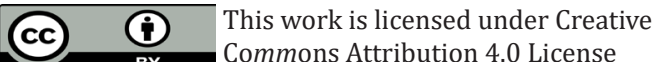

Submission Link: https://biomedres.us/submit-manuscript.php
104. David Sulzer, Roy N Alcalay, Francesca Garretti, Lucien Cote, Ellen Kanter, et al. (2017) T cells from patients with Parkinson's disease recognize alpha-synuclein peptides. Nature 546: 656-661.

105. Kumar DK, Choi SH, Washicosky KJ, Eimer WA, Tucker S, et al. (2016) Amyloid-beta peptide protects against microbial infection in mouse and worm models of Alzheimer's disease. Sci Transl Med 8(340): 340ra72.

\begin{tabular}{|ll}
\hline BIOMEDICAL & Assets of Publishing with us \\
\hline RESEARCHES & Global archiving of articles \\
\hline & - Immediate, unrestricted online access \\
\hline
\end{tabular}

